\title{
Mumps outbreaks across Canada, 2016 to 2018
}

\author{
Myriam Saboui ${ }^{1 *}$, Susan G Squires ${ }^{1}$
}

\begin{abstract}
Background: An increase in mumps incidence was observed in late 2016 (365 cases in 2016 compared to 59 cases in 2015). This unusual level of mumps activity prompted the Public Health Network Council and the National Advisory Committee on Immunization to request situation awareness updates from the Centre for Immunization and Respiratory Infectious Diseases (CIRID) at the Public Health Agency of Canada in 2017 and 2018.
\end{abstract}

Methods: A mumps outbreak survey was developed and administered by epidemiologists within CIRID and sent electronically to provincial and territorial public health officials in charge of mumps surveillance. The survey collected information on mumps outbreaks pertaining to demographics, risk factors, laboratory data and public health interventions. The first survey collected data on outbreaks occurring between January 1, 2016 and February 28, 2017, while the second survey contained outbreak data from January 1, 2017 to July 31, 2018. Duplicate outbreaks entries were removed.

Results: The response rate for the first and second surveys was $61 \%$ and $69 \%$, respectively. Twenty-four mumps outbreaks across nine provinces were reported between January 1, 2016 and July 31,2018 , for a cumulative total of 881 mumps cases. Adolescents and adults 15 to 39 years of age accounted for the majority of cases (80.6\%). Specifically, adults 20 to 24 years of age represented the largest proportion of cases (24.6\%). Community and social gatherings were the most common exposure setting (62.5\%). Slightly more than one third of cases were known to have received at least two doses of mumps-containing vaccine (35.6\%).

Conclusion: Results from the surveys indicate that the increase in mumps activity was widespread throughout Canada, affecting multiple jurisdictions. Young adults accounted for the largest proportion of cases. These surveys provided evidence to support recommendations on the use of additional mumps vaccination in outbreak settings.
This work is licensed under a Creative Commons Attribution 4.0 International License.

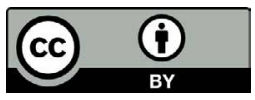

Affiliation

${ }^{1}$ Centre for Immunization and Respiratory Infectious Diseases, Public Health Agency of Canada, Ottawa, ON

*Correspondence:

myriam.saboui@canada.ca

Suggested citation: Saboui M, Squires SG. Mumps outbreaks across Canada, 2016 to 2018. Can Commun Dis Rep 2020;46(11/12):427-31. https://doi.org/10.14745/ccdr.v46i1112a10

Keywords: mumps, Canada, outbreak, survey

\section{Introduction}

Despite strong vaccination programs in all provinces and territories, mumps remains endemic in Canada, with outbreaks cycles occurring approximately every four to five years $(1,2)$. An increase in incidence beyond the expected trends across Canada was noted in 2016 (1-4). This increased activity resulted in significant public health resources being directed towards prevention and control of various local outbreaks. On February 23, 2017, the Public Health Network Council (PHNC) requested that the Public Health Agency of Canada (PHAC) organise a conference call with their provincial and territorial working level partners to share information regarding the outbreak. In addition, PHNC wanted to get a sense of the pan-Canadian epidemiology regarding the recent resurgence of mumps so that provinces and territories could tailor their approaches to address this situation. The Centre for
Immunization and Respiratory Infectious Diseases (CIRID) developed and distributed a survey to the provinces and territories (on February 25, 2020) to gather information on recent mumps outbreaks and public health responses to these outbreaks. On March 2, 2017, CIRID hosted a conference call with provinces and territories to present the results and discuss public health measures that provinces and territories had implemented to address the outbreaks.

In August 2018, during a Canadian Immunization Committee $(\mathrm{CIC})$ teleconference, the National Advisory Committee on Immunization (NACl) requested CIRID of PHAC to conduct a follow-up survey with the provinces and territories. The objective of this survey was to provide an update to the 2016/2017 pan-Canadian epidemiology and to support the work 
of the NACI Measles Mumps and Rubella Working Group to investigate the effectiveness of the vaccine and the number of doses required.

This report describes the results of these two surveys, conducted by $\mathrm{CIRID}$ within $\mathrm{PHAC}$, to inform $\mathrm{PHNC}$ and $\mathrm{NACl}$ regarding the pan-Canadian epidemiology of mumps resurgence between 2016 and 2018.

\section{Methods}

In February 2017, a survey was developed by CIRID staff to quantify and describe mumps outbreaks activity across Canada. The survey was developed using Microsoft Excel and collected demographic, risk factor, laboratory data and information on public health interventions on temporally defined outbreaks by province and territory. This survey was emailed to the "mumps leads" in all provinces and territories to collects mumps outbreak data between January 1, 2016 and February 28, 2017. A second survey was emailed to mumps leads in all provinces and territories in August 2018, using a slightly revised survey to reflect a new time period (January 2017-August 2018).

Surveys were sent in both English and French. Follow-up emails were conducted to improve response rates. Analyses were conducted using Microsoft Excel. Information on outbreak setting, demographics, vaccination status and genotype were summarized in counts and proportions. Duplicates were assessed by province/territory and removed prior to analysis.

Results presented are for the combined period of January 1, 2016 to July 31, 2018.

\section{Results}

The total response rate for these two surveys was $65 \%(n=17 / 26)$; $62 \%(n=8 / 13)$ for the first survey and $69 \%(n=9 / 13)$ for the second survey. Five provinces and territories responded to both surveys; one did not respond to either survey. Nine provinces reported one or more outbreaks during the survey period (British Columbia, Alberta, Saskatchewan, Manitoba, Ontario, Québec, New Brunswick, Nova Scotia and Newfoundland and Labrador) (Figure 1). Prince Edward Island, Northwest Territories and Nunavut reported no outbreaks during the survey period.

Among the nine provinces, a total of 24 outbreaks were reported during the survey period, affecting 881 people (Table 1). The number of outbreaks reported ranged from one to seven per province and the median number of outbreaks was two per province. For the 18 outbreaks for which the end date was provided at the time of the surveys, the median duration of outbreaks was 7.5 weeks and the median size was 12.5 cases (ranged from two to 166).
Figure 1: Duration and size of outbreaks by province ${ }^{a}$

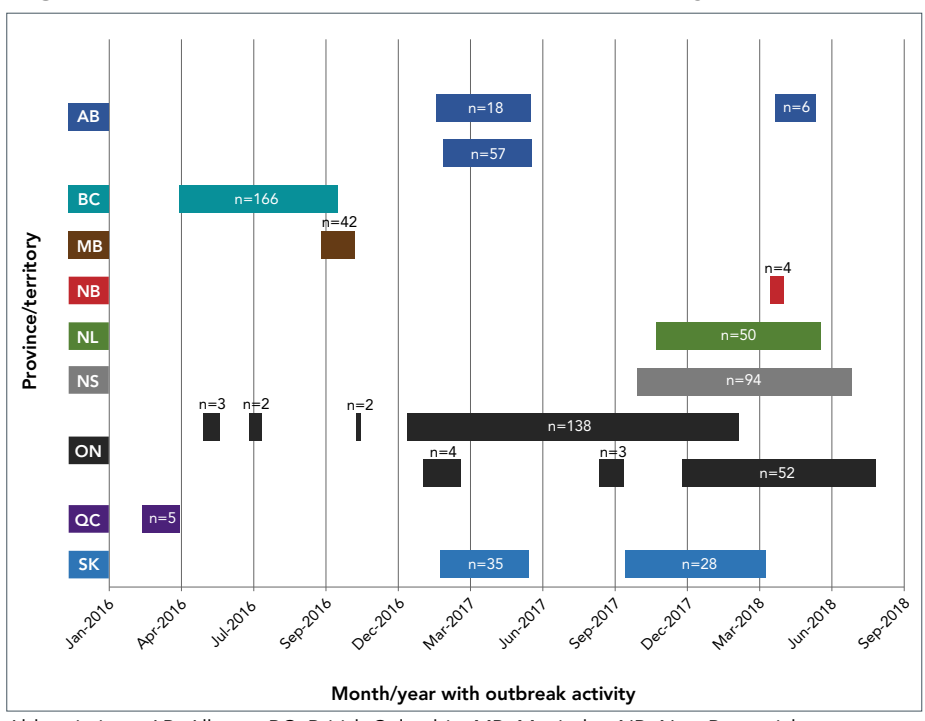

Abbreviations: AB, Alberta; BC, British Columbia; MB, Manitoba; NB, New Brunswick; NL, Newfoundland and Labrador; NS, Nova Scotia; ON, Ontario; QC, Québec; SK, Saskatchewan a Outbreaks with missing end dates are not shown

Table 1: Characteristics of outbreaks reported, January 1, 2016 to July 31, 2018

Indicator

Result

\begin{tabular}{|l|r|}
\hline Number of outbreaks & 24 \\
\hline Number of cases & 881 \\
\hline Median & 12.5 \\
\hline Range & $2-166$ \\
\hline Outbreak duration in weeks ${ }^{a}$ & \\
\hline Median & 7.5 \\
\hline Range & $1-59$ \\
\hline Number of outbreaks reported by province & \\
\hline Median & \\
\hline Range & 2 \\
\hline
\end{tabular}

a Outbreaks for which end dates were provided at the time of the surveys

Community and social gatherings were the most common exposure settings associated with outbreaks (62.5\%) (Table 2). Of the 814 cases for which age was known, adults 15 to 39 years of age accounted for the majority of reported cases (80.6\%) with the highest proportion among those 20 to 24 years of age (25\%). Children under the age of four years accounted for less than $2 \%$ of all cases (1.2\%). For cases where sex was reported, a slight majority of cases were reported in males (55\%). Fourteen of 24 outbreaks had genotype information; 11 were identified as being caused by genotype $\mathrm{G}$, one was identified as genotype $G$ and $C$ and two outbreaks were other genotypes. Vaccination status was unknown for approximately one third of cases (29\%). Among cases with known vaccination status, nearly half (49\%) reported having received two or more doses of the mumps vaccines, $30 \%$ had received one dose and $20 \%$ reported having never being vaccinated. 
Table 2: Descriptive summary of mumps outbreaks January 1, 2016 to July 31, 2018

\begin{tabular}{|c|c|c|c|}
\hline Category & Indicator & $\begin{array}{l}\text { Number of } \\
\text { cases }\end{array}$ & $\%$ \\
\hline \multirow{8}{*}{$\begin{array}{l}\text { Setting } \\
\text { (outbreak) }\end{array}$} & Community & 8 & 33.3 \\
\hline & Social gathering & 7 & 29.2 \\
\hline & Sports team & 5 & 20.8 \\
\hline & $\begin{array}{l}\text { Post-secondary } \\
\text { institution }\end{array}$ & 5 & 20.8 \\
\hline & Bars & 4 & 16.7 \\
\hline & Household/family & 4 & 16.7 \\
\hline & High school & 2 & 8.3 \\
\hline & Workplace & 2 & 8.3 \\
\hline \multirow[t]{12}{*}{ Age (years) } & Younger than 1 & 1 & 0.1 \\
\hline & $1-4$ & 9 & 1.0 \\
\hline & $5-9$ & 24 & 2.7 \\
\hline & $10-14$ & 23 & 2.6 \\
\hline & $15-19$ & 129 & 14.6 \\
\hline & $20-24$ & 217 & 24.6 \\
\hline & $25-29$ & 153 & 17.4 \\
\hline & $30-39$ & 157 & 17.8 \\
\hline & $40-49$ & 65 & 7.4 \\
\hline & $50-59$ & 27 & 3.1 \\
\hline & Older than or 60 & 9 & 1.0 \\
\hline & Unknown age & 67 & 7.6 \\
\hline \multirow[t]{3}{*}{ Sex } & Male & 487 & 55.3 \\
\hline & Female & 329 & 37.3 \\
\hline & Unknown sex & 65 & 7.4 \\
\hline \multirow{5}{*}{$\begin{array}{l}\text { Vaccination } \\
\text { status }\end{array}$} & Unvaccinated & 127 & 14.4 \\
\hline & 1 dose & 187 & 21.2 \\
\hline & 2 doses & 307 & 34.8 \\
\hline & 3 doses & 7 & 0.8 \\
\hline & $\begin{array}{l}\text { Unknown vaccination } \\
\text { status }\end{array}$ & 253 & 28.7 \\
\hline \multirow{4}{*}{$\begin{array}{l}\text { Genotype } \\
\text { (outbreak) }\end{array}$} & $\mathrm{G}$ & 11 & 45.8 \\
\hline & $G$ and $C$ & 1 & 4.2 \\
\hline & Other & 2 & 8.4 \\
\hline & Unknown & 10 & 41.7 \\
\hline
\end{tabular}

${ }^{a}$ Non-mutually exclusive settings

The most common public health intervention reported by provinces was a memo to public health authorities and clinicians and vaccination campaigns (Figure 2). Exclusions to schools/ healthcare settings and social media were the least frequent interventions reported.

\section{Figure 2: Public health interventions reported during} outbreaks

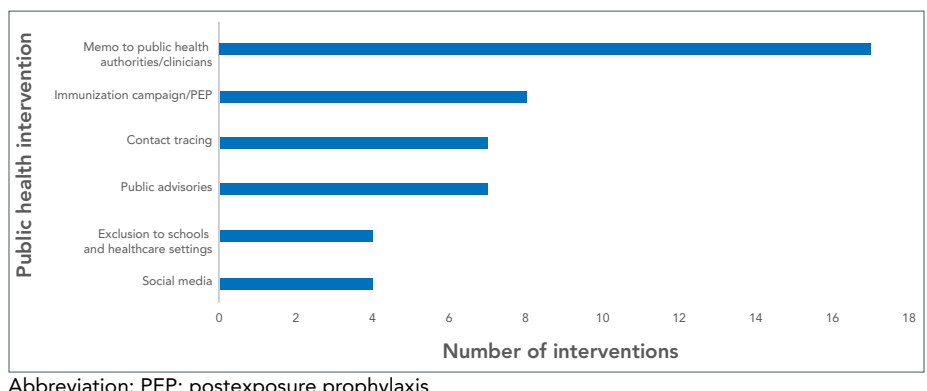

\section{Discussion}

Data on resurgence of measles in Canada in 2017 and 2018 were gathered from provinces and territories via two surveys that were sent to appropriate public health personnel. These outbreaks largely affected the young adult population (20-39 years of age), who had received at least one mumps-containing vaccine, and were linked to social gatherings and community settings. These results were consistent with those from other studies; young adults, even those who had been vaccinated, accounted for the majority of cases (4-8).

In Canada, the mumps vaccine is available only in combination with 1) the measles and rubella vaccine or 2) the measles, rubella and varicella vaccine. Although immunity to mumps is known to wane at a rate of approximately $10 \%$ per year following administration of the mumps vaccine booster, vaccination is still the best prevention strategy (9). Although the survey did not look at date of most recent dose of mumps containing vaccine, the largest proportion of cases with known vaccination status reported having received at least two doses of mumps containing vaccine.

This study did not evaluate the effectiveness of public health intervention strategies used by various provinces; it simply provided an inventory of what intervention strategies were used overall. Although social media campaigns were the least common public health intervention used during this study period, in the course of a recent outbreak in Ontario, social media was deemed highly successful as an intervention during the investigation (6). The efficiency of social media in terms of outreach was echoed in another study (10). Platforms such as Twitter and Facebook can be used as venues to diffuse information rapidly and to cater to a young audience; the population primarily affected in outbreaks.

The impetus of this study was to provide a situational awareness to senior public health officials across Canada through the PHNC. After validating the survey results with provincial and territorial mumps leads during a teleconference call in early March 2017, a briefing note was prepared and distributed to PHNC members 
(mid March 2017). Additionally, the combined survey results were presented to the NACl's Mumps Working Group in November 2018 and to $\mathrm{NACl}$ in February 2019 for consideration in their deliberations on recommending the use of an additional dose of mumps-containing vaccine during outbreaks.

A large mumps outbreak occurred in the province of Manitoba between September 2016 and November 6, 2018, with more than 2,000 cases (4). These data were not included in the pan-Canadian epidemiology surveys as the Manitoba outbreak had not ended by the time the second survey was distributed. The majority of cases were post-secondary students, between 18 and 29 years of age, living in Winnipeg (11). Exposure settings included university and sports settings. Vaccination status of cases was not reported. Although this outbreak was not reported using the survey tool, and therefore not included in the results of this current study, the epidemiology of the large Manitoba outbreak, in terms of age groups and risk settings, was consistent with what was reported in our survey (4).

\section{Strengths and limitations}

The results of these surveys represent a snapshot in time. Although the largest mumps outbreak that occurred in Canada during this time was neither reported nor included in this survey, the survey did provide useful data with respect to epidemiology of mumps outbreaks, specifically the age groups affected, vaccination status and exposure settings.

These surveys provided data that are not currently collected through national routine surveillance of mumps. National surveillance collects data related to age, reporting province/territory but not public health responses. They also provided timely data for public health decision-makers to inform public health actions aimed at reducing the spread and consequently the impacts of the mumps virus within our communities.

The largest mumps outbreak that occurred in Canada during this time was neither reported nor included in this survey. However, the survey did provide useful epidemiological data in terms of age groups affected, vaccination status and exposure settings.

The timing since the last dose of vaccine and the link to the increase in mumps activity has been studied previously and findings have been used to support policy change in vaccination programs (12-14). Neither the routine Canadian national surveillance data nor the enhanced data collected through these surveys were able to address this specific issue. Additionally, information on disease severity of mumps was not explored.

\section{Conclusion}

The outbreaks reported between 2016 and 2018 affected most provinces across Canada. Results from the surveys indicated that sustained transmission of mumps occurred, even in populations that received one or more doses of mumps-containing vaccine. This highlights the importance of examining other factors contributing to the sustained high levels of activity, such as the waning of immunity over time, and evaluating various public health strategies aimed at reducing the spread of mumps among populations at risk.

\section{Authors' statement}

MS - Formal analysis, writing-original draft, writing-review \& editing

SGS - Conception, design, and acquisition of data, drafting and revising of writing, critical review

\section{Competing interests}

No potential competing interests were disclosed.

\section{Acknowledgements}

The authors gratefully acknowledge the provincial and territorial public health agencies for providing data, and L Sherrard, M Roy, K Rutledge-Taylor and D MacDonald from the Public Health Agency of Canada for their work on this project.

\section{Funding}

No external funding was received.

\section{References}

1. Public Health Agency of Canada. Vaccine Preventable Disease: Surveillance Report to December 31, 2015. Ottawa (ON): PHAC; 2017. https://www.canada.ca/en/public-health/ services/publications/healthy-living/vaccine-preventabl e-disease-surveillance-report-december-31-2015.html

2. Public Health Agency of Canada. Supplement: Guidelines for the prevention and control of mumps outbreaks in Canada. Can Comm Dis Rep 2010;36(Supplement 1):1-49. https://www.canada.ca/en/public-health/services/ reports-publications/canada-communicable-disease-reportccdr/monthly-issue/2010-36/guidelines-preventio n-control-mumps-outbreaks-canada.html\#toc

3. Nunn A, Masud S, Krajden M, Naus M, Jassem AN. Diagnostic Yield of Laboratory Methods and Value of Viral Genotyping during an Outbreak of Mumps in a Partially Vaccinated Population in British Columbia, Canada. J Clin Microbiol 2018;56(5):e01954-17. DOI PubMed 
4. Wei Y, Wilkinson K, Rusk R, Kadkhoda K, Loeppky C. Large community mumps outbreak in Manitoba, Canada, September 2016-December 2018. Can Commun Dis Rep 2020;46(4):70-6. DOl PubMed

5. Westphal DW, Eastwood A, Levy A, Davies J, Huppatz C, Gilles M, Lyttle H, Williams SA, Dowse GK. A protracted mumps outbreak in Western Australia despite high vaccine coverage: a population-based surveillance study. Lancet Infect Dis 2019;19(2):177-84. DOI PubMed

6. Dubey V, Ozaldin O, Shulman L, Stuart R, Maclachlan J, Bromley L, Summers A. Investigation and management of a large community mumps outbreak among young adults in Toronto, Canada, January 2017-February 2018. Can Commun Dis Rep 2018;44(12):309-16. DOI PubMed

7. Patel LN, Arciuolo RJ, Fu J, Giancotti FR, Zucker JR, Rakeman JL, Rosen JB. Mumps Outbreak Among a Highly Vaccinated University Community-New York City, January-April 2014. Clin Infect Dis 2017;64(4):408-12. DOI PubMed

8. Willocks LJ, Guerendiain D, Austin HI, Morrison KE, Cameron RL, Templeton KE, DE Lima VR, Ewing R, Donovan W, Pollock KG. An outbreak of mumps with genetic strain variation in a highly vaccinated student population in Scotland. Epidemiol Infect 2017;145(15):3219-25. DOI PubMed
9. Principi N, Esposito S. Mumps outbreaks: A problem in need of solutions. J Infect 2018;76(6):503-6. DOI PubMed

10. Isaac BM, Zucker JR, MacGregor J, Asfaw M, Rakeman JL, Fu J, Deocharan B, Liu D, Rosen JB. Notes from the Field: Use of Social Media as a Communication Tool During a Mumps Outbreak - New York City, 2015. MMWR Morb Mortal Wkly Rep 2017;66(2):60-1. DOI PubMed

11. Manitoba Health, Seniors and Active Living. Mumps (accessed 2020-05-02). https://www.gov.mb.ca/health/ publichealth/diseases/mumps.html

12. Lewnard JA, Grad YH. Vaccine waning and mumps re-emergence in the United States. Sci Transl Med 2018;10(433):eaao5945. DOI PubMed

13. Cardemil CV, Dahl RM, James L, Wannemuehler K, Gary HE, Shah M, Marin M, Riley J, Feikin DR, Patel M, Quinlisk P. Effectiveness of a Third Dose of MMR Vaccine for Mumps Outbreak Control. N Engl J Med 2017;377(10):947-56. DOI PubMed

14. Vygen S, Fischer A, Meurice L, Mounchetrou Njoya I, Gregoris M, Ndiaye B, Ghenassia A, Poujol I, Stahl JP, Antona D, Le Strat Y, Levy-Bruhl D, Rolland P. Waning immunity against mumps in vaccinated young adults, France 2013. Euro Surveill 2016;21(10):30156. DOI PubMed

\section{PREVENT THE SPREAD OF COVID-19}
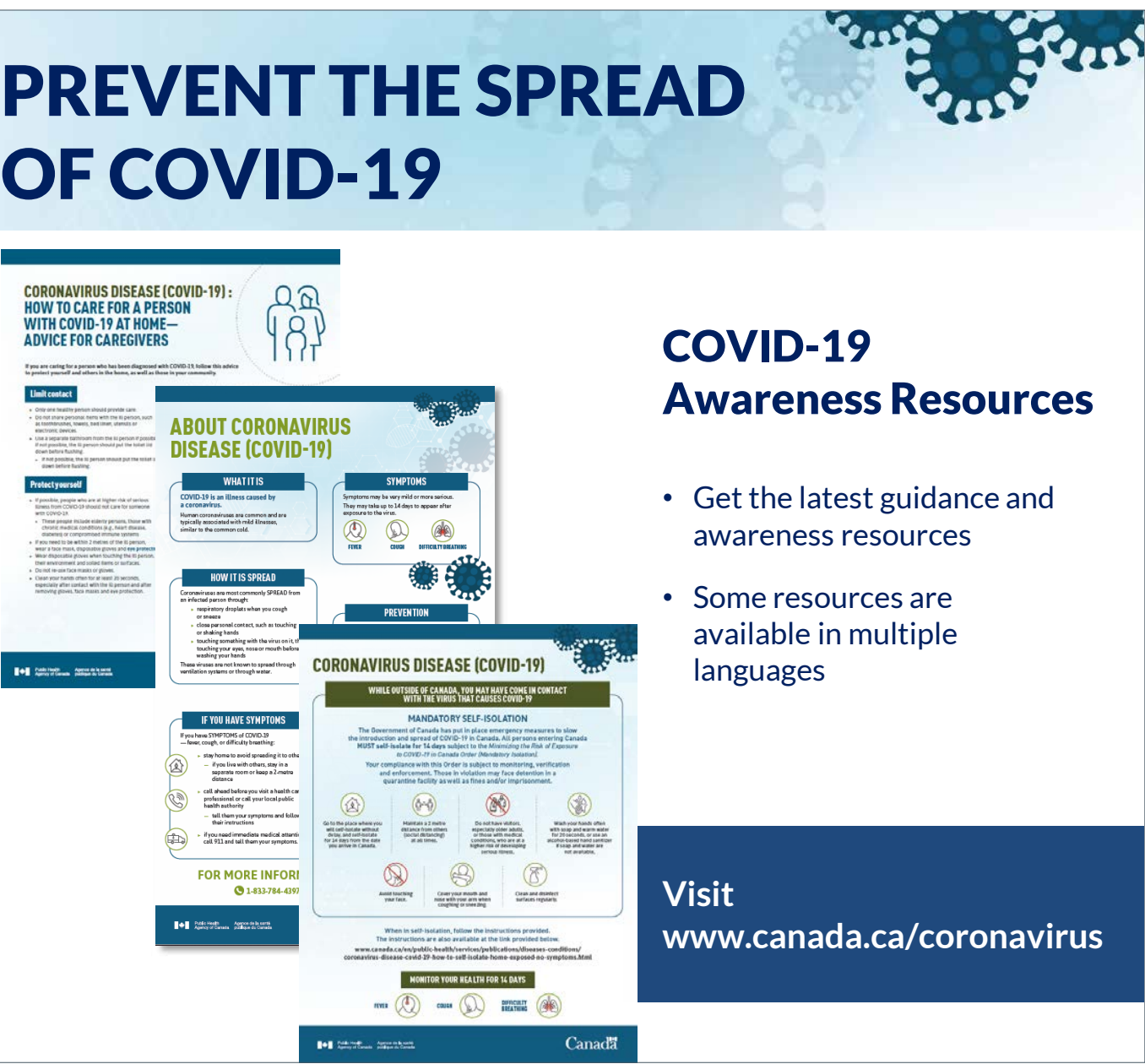